\title{
Alcohols, esters and heavy sulphur compounds production by pure and mixed cultures of apiculate wine yeasts
}

\author{
Nathalie Moreira, Filipa Mendes, Tim Hogg, Isabel Vasconcelos* \\ Escola Superior de Biotecnologia, Universidade Católica Portuguesa, Rua Dr. António Bernardino de Almeida, 4200-072, Porto, Portugal
}

Keywords: Hanseniaspora uvarum; Hanseniaspora guilliermondii; Saccharomyces cerevisiae; Secondary fermentation products; Heavy sulphur compounds

\begin{abstract}
Strains of Hanseniaspora uvarum, Hanseniaspora guilliermondii and Saccharomyces cerevisiae were used as pure or mixed starter cultures in commercial medium, in order to compare their kinetic parameters and fermentation patterns. In pure and mixed cultures, yeasts presented similar ethanol yield and productivity. Pure cultures of H. uvarum and S. cerevisiae showed a specific growth rate of $0.38 \mathrm{~h}^{-1}$; however, this value decreased when these yeasts were grown in mixed cultures with $H$. guilliermondii. The specific growth rate of pure cultures of $H$. guilliermondii was $0.41 \mathrm{~h}^{-1}$ and was not affected by growth of other yeasts. H. guilliermondii was found to be the best producer of 2-phenylethyl acetate and 2-phenylethanol in both pure and mixed cultures. In pure cultures, H. uvarum led to the highest contents of heavy sulphur compounds, but $H$. guilliermondii and $S$. cerevisiae produced similar levels of methionol and 2-methyltetrahydrothiophen-3-one. Growth of apiculate yeasts in mixed cultures with S. cerevisiae led to amounts of 3-methylthiopropionic acid, acetic acid-3-(methylthio)propyl ester and 2methyltetrahydrothiophen-3-one similar to those obtained in a pure culture of $S$. cerevisiae; however, growth of apiculate yeasts increased methionol contents of fermented media.
\end{abstract}

\section{Introduction}

Apiculate wine yeasts (Hanseniaspora uvarum and Hanseniaspora guilliermondii) have become an object of interest as they are frequently found in grapes and are also dominators of the early stages of

\footnotetext{
* Corresponding author. Tel.: +351 22 5580049; fax: +351 22 5090351 .

E-mail address: ivasc@esb.ucp.pt (I. Vasconcelos).
}

must fermentation (Kunkee, 1984; Gao and Fleet, 1988; Zironi et al., 1993; Gil et al., 1996; Fleet, 2003). Their intolerance to high concentrations of ethanol, the high sugar concentration and the low available oxygen conditions during fermentation are the main reasons why Saccharomyces cerevisiae becomes dominant and keeps its activity until the end of fermentation (Goto, 1980; Fleet et al., 1984; Heard and Fleet, 1985; Martinez et al., 1989; Fleet and Heard, 1993; Schütz and Gafner, 1993; Lema et al., 
1996; Constantí et al., 1997; Egli et al., 1998; Hansen et al., 2001).

Growth of apiculate yeasts with $S$. cerevisiae must be considered because it may influence the sensory quality of wine. Some studies evaluated the production of fermentation compounds by pure, mixed or sequential cultures of apiculate yeasts with $S$. cerevisiae strains, using either grape must or basal synthetic medium (Herraiz et al., 1990; Mateo et al., 1991; Velázquez et al., 1991; Zironi et al., 1993; Ciani and Picciotti, 1995; Gil et al., 1996; Romano et al., 1997a,b; Ciani and Maccarelli, 1998; Rojas et al., 2001, 2003; Zohre and Erten, 2002; Romano et al., 2003). These experiments showed that there are significant differences in chemical composition of the resulting wines or fermented media. However, there is considerable controversy concerning the effect of growth of apiculate yeasts on the organoleptic quality of wines. Ciani and Picciotti (1995) exclude the possibility of using apiculate yeasts in winemaking, due to the production of large amounts of ethyl acetate and acetic acid. Gil et al. (1996) observed that wines produced with mixed cultures presented a higher concentration of alcohols and acids, in contrast with those fermented with pure cultures of $S$. cerevisiae. However, Herraiz et al. (1990) found a higher content in higher alcohols in wines fermented with Saccharomyces spp. than in those fermented with pure cultures of apiculate yeasts. Experiments performed by Rojas et al. (2001, 2003) reported that $H$. guilliermondii 11104 (CECT, Spain) was a strong producer of 2-phenylethyl acetate. According to Romano et al. (1997a,b, 2003), the synthesis of secondary products is an individual and reproducible strain characteristic.

Sulphur compounds comprise a structurally diverse class of molecules that provides a whole range of characteristic aromatic notes. Generally, the aromatic contributions of these compounds are considered detrimental to wine quality (Anocibar Beloqui and Bertrand, 1995; Mestres et al., 2000); however, new developments in wine research allowed the differentiation of a family of sulphur compounds responsible for a varietal aroma of wines. The formation of sulphur compounds is affected by the organic and inorganic Scontaining substances and pesticides in grape musts, by the nutrient level of grape musts and by the yeast metabolism during fermentation (Rauhut, 1993). Very few reports are available in literature concerning the production of sulphur compounds by non-Saccharomyces yeasts. In a study performed by Romano et al. (1997b), several strains of Kloeckera apiculata and $H$. guilliermondii were compared according to the production of sulphur dioxide and hydrogen sulphide in a basal synthetic medium. These authors observed that all strains produced less than $10 \mathrm{mg}^{-1}$ of sulphur dioxide and that $K$. apiculata produced higher amounts of hydrogen sulphide than $H$. guilliermondii.

In order to understand the effect of growth of apiculate yeasts and how they contribute to the final composition of fermented media, experiments were conducted using pure and mixed cultures of $H$. guilliermondii, $H$. uvarum and $S$. cerevisiae. The $H$. guilliermondii strain studied was isolated from grape musts of the Douro region, in Portugal. Fermentation kinetic parameters and the production of secondary metabolites were evaluated in pure and mixed cultures. Special attention was given to the heavy sulphur compounds production profiles of Hanseniaspora strains, as, to our knowledge, analysis of heavy sulphur compounds produced by apiculate yeasts was never reported. A basal commercial medium was used to characterize the fermentation pattern of Hanseniaspora strains in order to avoid interferences of grape must composition and provide easily reproducible growth conditions. Growth of Hanseniaspora strains on simple media may help to explain results obtained on grape musts fermentations.

\section{Materials and methods}

\section{Yeast strains}

The strains used in this study were $H$. guilliermondii NCYC 2380 (National Collection of Yeast Cultures, Norwich, UK), H. uvarum PYCC 4193T and S. cerevisiae PYCC 3507 (Portuguese Yeast Culture Collection, Instituto Gulbenkian da Ciência, Oeiras, Portugal). Yeasts were maintained on Yeast Malt agar slants (YM agar, Difco Laboratories, Detroit, IN, USA).

\section{Fermentations}

Pure cultures of $H$. guilliermondii (Hg), H. uvarum $(\mathrm{Hu})$ and $S$. cerevisiae $(\mathrm{Sc})$ and mixed cultures $(\mathrm{Hu}-$ 
$\mathrm{Hg}, \mathrm{Hu}-\mathrm{Sc}, \mathrm{Hg}-\mathrm{Sc}, \mathrm{Hu}-\mathrm{Hg}-\mathrm{Sc}$ ) were carried out in $200 \mathrm{ml}$ of YM medium (Difco Laboratories, Detroit, IN, USA), with approximately $10 \mathrm{~g}^{-1}$ of glucose, at $25{ }^{\circ} \mathrm{C}$, under gentle agitation $(80 \mathrm{rpm})$. Each experiment was reproduced four times. Inocula of each yeast strain were previously grown at $25{ }^{\circ} \mathrm{C}$ for $24 \mathrm{~h}$ in $\mathrm{YM}$ medium. The inoculation of media was carried out in order to obtain an initial cell concentration of $10^{5}-10^{6}$ cfu $\mathrm{ml}^{-1}$ of each strain.

\section{Enumeration of yeast populations}

According to the characteristics of each yeast species, as defined by Barnett et al. (1990), it was possible to define selective media and incubation conditions that allow the differentiation of each yeast species. The number of yeast cells, expressed as cfu $\mathrm{ml}^{-1}$, was determined using the pour plate method, after incubation of plates at specific temperatures for $48 \mathrm{~h}$. The medium used was YM agar with or without addition of a selective component. YM agar allows the enumeration of viable yeast cells of all tested strains, after incubation at $25^{\circ} \mathrm{C}$; if incubation is performed at $37{ }^{\circ} \mathrm{C}$ only $H$. guilliermondii and $S$. cerevisiae will grow, due to the growth inhibition of H. uvarum at this temperature. Plates of YM agar with $0.01 \%$ of cycloheximide (Sigma Chemical, St Louis, MO, USA) were used as a selective medium for Hanseniaspora enumeration, after incubation at $25{ }^{\circ} \mathrm{C}$. Incubation of plates of YM agar with $0.01 \%$ of cycloheximide at $37^{\circ} \mathrm{C}$ only allows growth of $H$. guilliermondii.

When mixed cultures were tested, plates of YM agar, incubated at $25{ }^{\circ} \mathrm{C}$, were used for total cell enumeration. For mixed cultures of $H$. uvarum and $S$. cerevisiae, plates of $\mathrm{YM}$ agar at $37{ }^{\circ} \mathrm{C}$ were used for counting $S$. cerevisiae cells, whereas plates of YM agar with $0.01 \%$ of cycloheximide, incubated at 25 ${ }^{\circ} \mathrm{C}$, were used for the enumeration of $H$. uvarum. In mixed cultures of $H$. guilliermondii and $H$. uvarum, it is only possible to count $H$. guilliermondii cells by incubating plates of YM agar with cycloheximide $(0.01 \%)$ at $37{ }^{\circ} \mathrm{C}$; the number of $\mathrm{H}$. uvarum cells was estimated by the difference between total cell number and the number of $H$. guilliermondii cells. A similar procedure was applied for mixed cultures of $H$. guilliermondii and $S$. cerevisiae; the number of $S$. cerevisiae cells was estimated by the difference between total cell number and the number of $H$. guilliermondii cells. For mixed cultures of all yeast strains, the number of $H$. uvarum cells was obtained by the difference between the total cell number obtained in YM agar with cycloheximide at $25{ }^{\circ} \mathrm{C}$ and the number of $H$. guilliermondii cells (YM agar with cycloheximide at $37{ }^{\circ} \mathrm{C}$ ); the number of $S$. cerevisiae cells was obtained by the difference between the total cell number obtained in YM agar at $37^{\circ} \mathrm{C}$ and the number of $H$. guilliermondii cells.

\section{Analytical determinations}

After fermentation, yeast cells were removed by centrifugation at $8000 \mathrm{rpm}$ and $4{ }^{\circ} \mathrm{C}$ for $15 \mathrm{~min}$. The supernatant was analysed using chromatographic procedures, according to the following methods.

The concentration of ethanol was determined by High Performance Liquid Chromatography using a Beckman, System Gold. Separation was performed on an Aminex ${ }^{\mathrm{R}} \mathrm{HPX}-87 \mathrm{H}$ column $(300 \times 7.8 \mathrm{~mm}$, Bio$\mathrm{Rad}$ ) and detection was assessed by refractive index. The mobile phase was a $0.5 \mathrm{mM}$ sulphuric acid solution, with a flow rate of $0.5 \mathrm{ml} \mathrm{min}{ }^{-1}$, at $30{ }^{\circ} \mathrm{C}$.

Higher alcohols, ethyl acetate and acetaldehyde were analysed using a Hewlett-Packard 5890 gas chromatograph equipped with a flame ionisation detector and connected to an H.P. 3396 Integrator. $50 \mu \mathrm{l}$ of 4-methyl-2-pentanol at $10 \mathrm{~g} \mathrm{l}^{-1}$ were added to $5 \mathrm{ml}$ of fermented medium as an internal standard. The sample $(1 \mu \mathrm{l})$ was injected (split, 1:60) into a CPWAX 57 CB column (Chrompack) of $50 \mathrm{~m} \times 0.25 \mathrm{~mm}$ and $0.2 \mu \mathrm{m}$ phase thickness. The temperature program was $40{ }^{\circ} \mathrm{C}(5 \mathrm{~min})$ to $180{ }^{\circ} \mathrm{C}(0 \mathrm{~min})$ at $3{ }^{\circ} \mathrm{C} \mathrm{min}^{-1}$. Injector and detector temperatures were set at $250{ }^{\circ} \mathrm{C}$. Carrier gas was $\mathrm{H}_{2}$ at $1 \mathrm{ml} \mathrm{min}{ }^{-1}$.

The determination of 2-phenylethyl acetate and 2phenylethanol was performed in a Perkin-Elmer Autosystem, equipped with a flame ionisation detector. $50 \mathrm{ml}$ of sample, with 4-decanol at $1.5 \mathrm{mg} \mathrm{l}^{-1}$ as internal standard, was extracted successively with 4,2 and $2 \mathrm{ml}$ of ether-hexane $(1: 1 \mathrm{v} / \mathrm{v})$ for $5 \mathrm{~min}$. The organic phase $(1 \mu \mathrm{l})$ was injected (splitless, $0.3 \mathrm{~min}$ ) into a CP-WAX 58 (FFAP)-CB column (Chrompack) of $50 \mathrm{~m} \times 0.32 \mathrm{~mm}$ and $0.3 \mu \mathrm{m}$ phase thickness. Temperature program was $40{ }^{\circ} \mathrm{C}(5 \mathrm{~min})$ to $220{ }^{\circ} \mathrm{C}$ (20 min) at $2{ }^{\circ} \mathrm{C} \mathrm{min}^{-1}$. Injector and detector temperatures were set $250{ }^{\circ} \mathrm{C}$. The carrier gas used was $\mathrm{H}_{2}$ at $1-2 \mathrm{ml} \mathrm{min}^{-1}$. 
2-Methyltetrahydrothiophen-3-one, acetic acid-3(methylthio)propyl ester, methionol (3-(methylthio)-1propanol) and 3-(methylthio)propionic acid were determined according to the method described by Moreira et al. (2004). The concentrations of commercially available sulphur compounds were expressed as $\mu \mathrm{g}^{-1}$. For those compounds whose reference standard was not available, the amounts were expressed as the ratio of peak area/peak area of internal standard.

For each analysed compound, the response of the detector was obtained using several standard solutions with different concentrations. The reproducibility of each method was assessed from several analyses of the same sample.

\section{Statistical analysis}

An analysis of variance (ANOVA) was applied to the experimental data; results were considered significant if the associated $P$ value was below 0.05 . The significant differences were determined by Tukey tests. All statistical analyses were performed using the software SPSS for Windows, version 10.0.

\section{Results and discussion}

Experiments were performed in order to evaluate the fermentation kinetic parameters and the production of higher alcohols, esters and heavy sulphur compounds by $H$. uvarum, $H$. guilliermondii and $S$. cerevisiae in pure and mixed cultures. Experiments were conducted using commercial medium so that results could be easier reproduced and compared.

\section{Enumeration of yeast population}

The viable number of cells was determined for each sample of fermentation broth. Results obtained on the different media used for cell enumeration (YM agar and $\mathrm{YM}+$ cycloheximide), at two incubation temperatures $\left(25\right.$ and $37{ }^{\circ} \mathrm{C}$ ), were analysed using the ANOVA analysis. For pure and mixed cultures, in conditions where the strains were able to grow, no significant differences in cell enumeration were found related to the growth medium or temperature of incubation used.

When mixed cultures of $H$. uvarum and $S$. cerevisiae were tested, the total cell number and the sum of $S$. cerevisiae and $H$. uvarum cell numbers were not significantly different. In mixed cultures of all strains, again no significant differences were found between the total cell number and the sum of $S$. cerevisiae, $H$. guilliermondii and $H$. uvarum cell numbers.

\section{Growth behaviour}

Growth kinetics and ethanol production by each yeast strain was followed during fermentation. Figs. 1 and 2 represent the evolution of yeast population
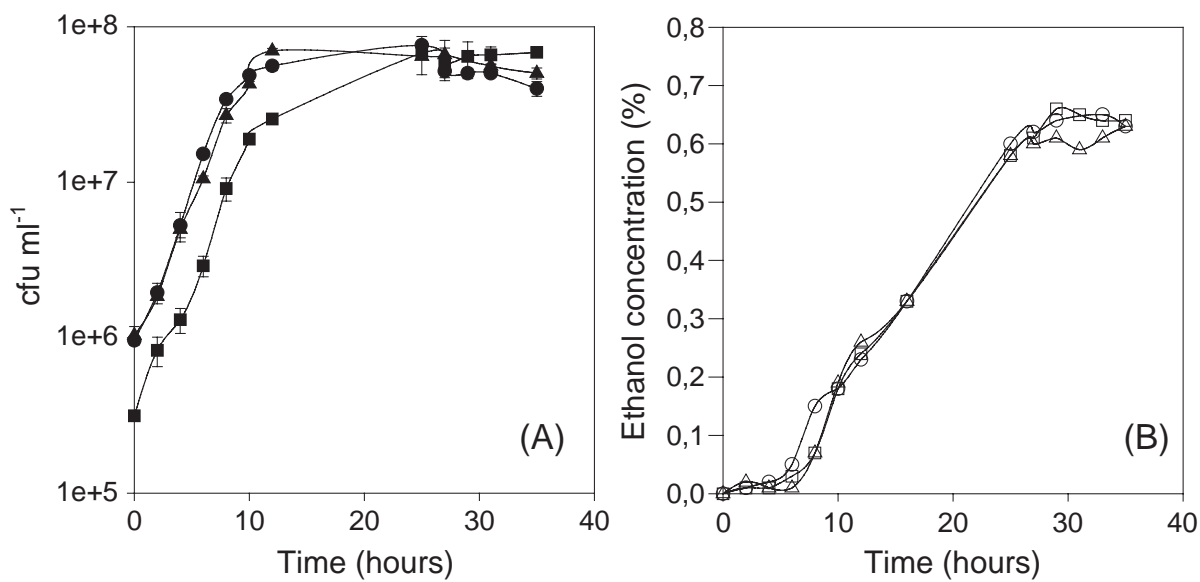

Fig. 1. Growth kinetics (A) and ethanol production (B) by pure cultures of S. cerevisiae $(\mathbf{\square}, \square), H$. guilliermondii $(\bullet, \bigcirc)$ and $H$. uvarum $(\boldsymbol{\Delta}, \triangle)$ on a commercial medium. Values for colony forming units are the average values of results obtained from four fermentations. Vertical bars represent standard deviation. 

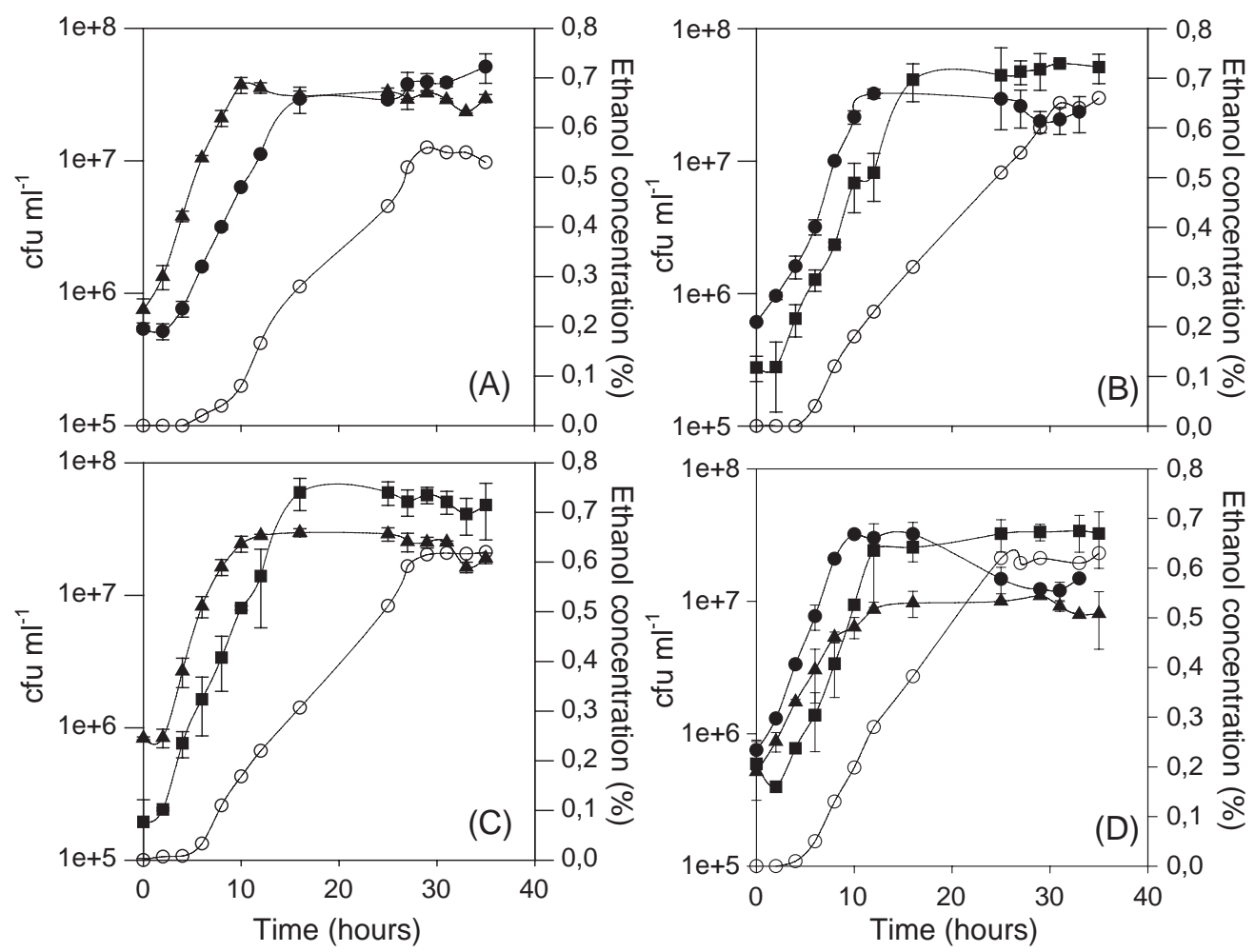

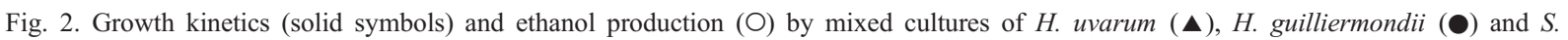
cerevisiae (ם) on a commercial medium. (A) H. uvarum and H. guilliermondii, (B) S. cerevisiae and H. guilliermondii, (C) S. cerevisiae and $H$. uvarum and (D) S. cerevisiae, H. guilliermondii and H. uvarum. Values for colony forming units are the average values of results obtained from four fermentations. Vertical bars represent standard deviation.

when respectively pure and mixed cultures were used. After a short lag phase, yeasts started the exponential growth, increasing the viable population to $10^{7}-10^{8}$ cfu $\mathrm{ml}^{-1}$. In pure or mixed cultures, apiculate yeasts achieved its highest cell mass concentration after approximately $8-12 \mathrm{~h}$ of fermentation, and started the decline phase after approximately $30 \mathrm{~h}$ of fermentation. In general, H. uvarum attained this phase earlier than $H$. guilliermondii, whereas $S$. cerevisiae kept its activity for a longer period.

In pure cultures, the specific growth rate of $S$. cerevisiae and $H$. uvarum was $0.38 \mathrm{~h}^{-1}$ (Table 1). $H$. guilliermondii presented a slightly higher specific growth rate value of $0.41 \mathrm{~h}^{-1}$. In mixed cultures, the specific growth rate of $H$. guilliermondii was not affected; however, in mixed culture of all yeasts, the specific growth rates of $S$. cerevisiae and $H$. uvarum decreased to $0.33 \mathrm{~h}^{-1}$ and $0.26 \mathrm{~h}^{-1}$, respectively. Only a few studies reported the kinetic parameters of wine yeasts. Experiments performed by Charoenchai et al. (1998), in a chemically defined grape juice medium, showed specific growth rates of $0.16-0.17$ $\mathrm{h}^{-1}$ for $S$. cerevisiae and $0.15-0.17 \mathrm{~h}^{-1}$ for $K$. apiculata (values estimated from plots of the log of optical density against time, using the straight line of the exponential growth phase). Ciani and Picciotti (1995), using a modified grape juice, reported specific growth rates of $0.14 \mathrm{~h}^{-1}$ for H. uvarum, $0.23 \mathrm{~h}^{-1}$ for $K$. apiculata and $0.26 \mathrm{~h}^{-1}$ for $S$. cerevisiae.

Under the conditions tested, ethanol productivity and ethanol yield obtained for apiculate yeasts were similar to those found in pure cultures of $S$. cerevisiae (Table 1). The main difference was found in the fermentation carried out with a mixed culture of apiculate yeasts. This culture exhibited the lowest values for ethanol yield $(41 \%)$ and ethanol productivity $\left(0.14 \mathrm{~g} \mathrm{l}^{-1} \mathrm{~h}^{-1}\right)$. According to Ciani and Picciotti (1995), H. uvarum, K. apiculata and $S$. 
Table 1

Fermentation parameters of pure and mixed cultures of H. uvarum $(\mathrm{Hu})$, H. guilliermondii $(\mathrm{Hg})$ and S. cerevisiae (Sc) on a commercial medium

\begin{tabular}{|c|c|c|c|c|c|c|c|}
\hline \multirow{2}{*}{$\begin{array}{l}\text { Fermentation } \\
\text { parameters }\end{array}$} & \multicolumn{3}{|c|}{ Pure cultures } & \multicolumn{4}{|c|}{ Mixed cultures } \\
\hline & $\mathrm{Hu}$ & $\mathrm{Hg}$ & $\mathrm{Sc}$ & $\mathrm{Hu}-\mathrm{Hg}$ & $\mathrm{Hu}-\mathrm{Sc}$ & $\mathrm{Hg}-\mathrm{Sc}$ & $\mathrm{Hu}-\mathrm{Hg}-\mathrm{Sc}$ \\
\hline $\begin{array}{l}\text { Ethanol production } \\
\qquad(\%, \mathrm{v} / \mathrm{v})\end{array}$ & $\begin{array}{l}0.60 \\
(0.03)\end{array}$ & $\begin{array}{l}0.64 \\
(0.02)\end{array}$ & $\begin{array}{l}0.67 \\
(0.02)\end{array}$ & $\begin{array}{l}0.54 \\
(0.01)\end{array}$ & $\begin{array}{l}0.62 \\
(0.02)\end{array}$ & $\begin{array}{l}0.65 \\
(0.02)\end{array}$ & $\begin{array}{l}0.61 \\
(0.02)\end{array}$ \\
\hline$Y_{\text {eth }}(\%, w / w)$ & 45 & 48 & 50 & 41 & 46 & 48 & 46 \\
\hline$Q_{\text {eth }}\left(\mathrm{g}^{-1} \mathrm{~h}^{-1}\right)$ & 0.15 & 0.16 & 0.17 & 0.14 & 0.16 & 0.16 & 0.16 \\
\hline
\end{tabular}

\begin{tabular}{|c|c|c|c|c|c|c|c|c|c|c|c|c|}
\hline \multirow[t]{2}{*}{$Q_{\text {eth }}\left(\mathrm{g}^{-1} \mathrm{~h}^{-1}\right)$} & \multirow[t]{2}{*}{0.15} & \multirow[t]{2}{*}{0.16} & \multirow[t]{2}{*}{0.17} & \multicolumn{2}{|l|}{0.14} & \multicolumn{2}{|l|}{0.16} & \multicolumn{2}{|l|}{0.16} & \multicolumn{2}{|l|}{0.16} & \multirow[b]{2}{*}{$\mathrm{Sc}$} \\
\hline & & & & $\mathrm{Hu}$ & $\mathrm{Hg}$ & $\mathrm{Hu}$ & $\mathrm{Sc}$ & $\mathrm{Hg}$ & $\mathrm{Sc}$ & $\mathrm{Hu}$ & $\mathrm{Hg}$ & \\
\hline$\mu_{\mathrm{x}}\left(\mathrm{h}^{-1}\right)$ & $\begin{array}{l}0.38 \\
(0.02)\end{array}$ & $\begin{array}{l}0.41 \\
(0.02)\end{array}$ & $\begin{array}{l}0.38 \\
(0.04)\end{array}$ & $\begin{array}{l}0.33 \\
(0.06)\end{array}$ & $\begin{array}{l}0.40 \\
(0.05)\end{array}$ & $\begin{array}{l}0.39 \\
(0.04)\end{array}$ & $\begin{array}{l}0.40 \\
(0.02)\end{array}$ & $\begin{array}{l}0.42 \\
(0.03)\end{array}$ & $\begin{array}{l}0.37 \\
(0.03)\end{array}$ & $\begin{array}{l}0.26 \\
(0.01)\end{array}$ & $\begin{array}{l}0.41 \\
(0.03)\end{array}$ & $\begin{array}{l}0.33 \\
(0.05)\end{array}$ \\
\hline
\end{tabular}

Values in parenthesis are standard deviations from four determinations; $Y_{\text {eth }}=$ ethanol yield (ratio between the maximum ethanol level produced and the initial sugar concentration of the media); $Q_{\text {eth }}=$ ethanol productivity (ratio between maximum ethanol produced and fermentation time, considered as the moment where ethanol concentration became constant); $\mu_{\mathrm{x}}=$ maximum specific growth rate (slope of the least square regression line of the natural logarithm of cell number vs. time data during the exponential growth phase).

cerevisiae presented ethanol yields of $0.47,0.53$ and $0.61\left(\mathrm{ml} \mathrm{g}^{-1}\right)$ respectively, and ethanol productivities of $0.48,0.51$ and $1.36 \mathrm{ml} \mathrm{l}^{-1} \mathrm{~h}^{-1}$ respectively in a modified grape juice.

\section{Composition of the fermented media}

\section{Higher alcohols}

No significant differences in 1-propanol, 2-methyl1-butanol and 3-methyl-1-butanol concentrations were observed in the media fermented by pure or mixed cultures (Table 2). The fermented media by a pure culture of $S$. cerevisiae presented a higher content in 2-methyl-1-propanol than those obtained from pure cultures of $H$. uvarum and $H$. guilliermondii (Fig. 3A); however, the content in 2-methyl-1-propanol was similar in mixed cultures. No significant differences were also obtained for the higher alcohols total concentration of fermented media. Similar results were obtained by Romano et al. (1997a) using a basal synthetic medium, where apiculate yeasts produced $1.4-6.1 \mathrm{mg} \mathrm{l}^{-1}$ of 1-propanol, 5.2-11.2 $\mathrm{mg} \mathrm{l}^{-1}$ of 2methyl-1-propanol, 7.7-12.6 $\mathrm{mg}^{-1}$ of 2-methyl-1butanol and 18.5-23.2 $\mathrm{mg} \mathrm{l}^{-1}$ of 3-methyl-1-butanol. In wines, higher alcohols are quantitatively dominant and important in the sensory properties and quality. Below $300 \mathrm{mg} \mathrm{l}^{-1}$ higher alcohols contribute positively to wine quality, while excessive amounts (higher than $400 \mathrm{mg}^{-1}$ ) may detract quality (Soufleros and Bertrand, 1979; Rapp and Versini, 1991; Lambrechts and Pretorius, 2000).

\section{Acetaldehyde and ethyl acetate}

No significant differences in ethyl acetate were obtained in media fermented by pure or mixed cultures (Table 2). Variations in acetaldehyde con-

Table 2

Concentration of major volatile compounds produced by pure and mixed cultures of H. uvarum (Hu), H. guilliermondii (Hg) and S. cerevisiae (Sc) on a commercial medium

\begin{tabular}{|c|c|c|c|c|c|c|c|c|}
\hline \multirow[t]{2}{*}{ Concentration $\left(\mathrm{mg} \mathrm{l}^{-1}\right)$} & \multicolumn{3}{|l|}{ Pure cultures } & \multicolumn{4}{|c|}{ Mixed cultures } & \multirow[t]{2}{*}{ Sig. } \\
\hline & $\mathrm{Hu}$ & $\mathrm{Hg}$ & $\mathrm{Sc}$ & $\mathrm{Hu}-\mathrm{Hg}$ & $\mathrm{Hu}-\mathrm{Sc}$ & $\mathrm{Hg}-\mathrm{Sc}$ & $\mathrm{Hu}-\mathrm{Hg}-\mathrm{Sc}$ & \\
\hline 1-Propanol & $5.06(0.43)$ & $6.42(1.90)$ & $6.94(1.21)$ & $5.01(0.79)$ & $6.11(1.46)$ & $5.06(0.43)$ & $6.15(0.86)$ & ns \\
\hline 2-Methyl-1-butanol & $10.8(3.1)$ & $11.6(0.9)$ & $11.5(0.5)$ & $9.78(0.68)$ & $9.86(2.15)$ & $10.9(2.3)$ & $10.1(0.5)$ & ns \\
\hline 3-Methyl-1-butanol & $14.8(4.3)$ & $19.5(4.6)$ & $11.8(2.4)$ & $12.8(2.6)$ & $17.2(3.3)$ & $14.8(3.2)$ & $17.2(3.0)$ & ns \\
\hline Total higher alcohols & $39.4(8.8)$ & $45.0(9.2)$ & $42.8(5.4)$ & $33.2(4.5)$ & $40.6(8.5)$ & $39.5(6.9)$ & $41.7(6.0)$ & $\mathrm{ns}$ \\
\hline Ethyl acetate & $9.07(0.12)$ & $9.74(0.21)$ & $9.85(1.46)$ & $6.77(0.11)$ & $9.33(2.11)$ & $9.07(0.12)$ & $9.30(1.91)$ & ns \\
\hline Acetaldehyde & $68.7(7.2)^{\mathrm{a}, \mathrm{b}}$ & $78.7(12.6)^{\mathrm{b}}$ & $93.4(3.2)^{\mathrm{b}}$ & $81.1(5.2)^{\mathrm{b}}$ & $39.5(1.3)^{\mathrm{a}}$ & $68.7(3.3)^{\mathrm{a}, \mathrm{b}}$ & $57.7(5.4)^{\mathrm{a}, \mathrm{b}}$ & $\dagger$ \\
\hline
\end{tabular}

Values in parenthesis are standard deviations from four determinations; Sig.: significance, $\dagger$ displays the significance at $1 \%$, ns - not significant; values not sharing the same superscript letter $(a, b)$ within the horizontal line are different according to the Tukey test. 

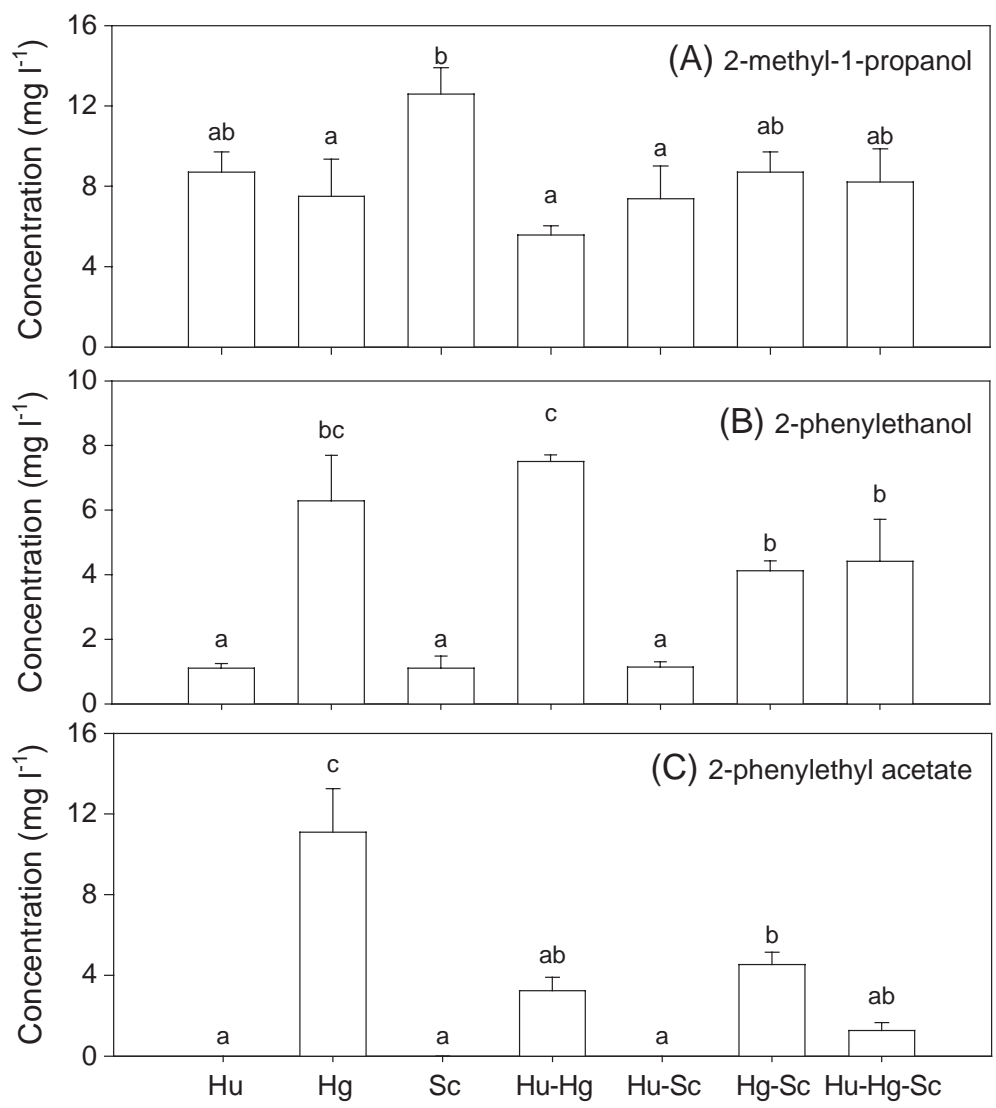

Fig. 3. Concentration of (A) 2-methyl-1-propanol, (B) 2-phenylethanol and (C) 2-phenylethyl acetate in pure and mixed cultures of H. uvarum $(\mathrm{Hu}), H$. guilliermondii $(\mathrm{Hg})$ and $\mathrm{S}$. cerevisiae $(\mathrm{Sc})$ on a commercial medium. Values not sharing the same superscript letter on top bar are different according to the Tukey test. Vertical bars represent standard deviation.

centrations were observed, but it was not possible to correlate them to the experiments performed. Romano et al. (1997a,b) also found different contents in acetaldehyde and ethyl acetate in synthetic media fermented by different apiculate yeast strains. Studies performed using grape musts inoculated with apiculate yeasts showed that the resulting wines presented large amounts of these compounds, including acetic acid (Benda, 1982; Herraiz et al., 1990; Ciani and Maccarelli, 1998; Schütz and Gafner, 1993). Excessively high contents of ethyl acetate do not improve the aroma of young wines, but at low contents $\left(50-80 \mathrm{mg} \mathrm{l}^{-1}\right)$ it contributes to wine quality (Ribéreau-Gayon et al., 2000); it has also been reported that the negative effect of high levels of this compound may be reduced during bottle aging (Lilly et al., 2000).

\section{2-Phenylethanol and 2-phenylethyl acetate}

The analysis of variance of data shows a significant effect of the yeast strain on the amount of 2-phenylethanol and 2-phenylethyl acetate in the fermented media (Fig. 3B and C). The highest concentrations of these compounds were observed in media fermented by pure and mixed cultures of $H$. guilliermondii. In pure cultures, this species was able to produce $6.30 \mathrm{mg} \mathrm{l}^{-1}$ of 2-phenylethanol, while $H$. uvarum and $S$. cerevisiae produced less than $1.12 \mathrm{mg}^{-1}$. In mixed cultures with $H$. guilliermondii, a high content in 2-phenylethanol was obtained, reaching $7.50 \mathrm{mg}^{-1}$ in media fermented by apiculate yeasts. 2-Phenylethyl acetate was only detected in pure and mixed cultures of $H$. guilliermondii. In pure culture, $H$. guilliermondii produced $11.1 \mathrm{mg}^{-1}$ of this compound. Rojas et al. (2001), 
using a synthetic medium, under anaerobic conditions, also reported that $H$. guilliermondii 11104 produced $28.9 \mathrm{mg}^{-1}$ of 2-phenylethyl acetate, whereas fermented media by pure cultures of $H$. uvarum 1444 and $S$. cerevisiae $\mathrm{T}_{73}$ only presented $0.22 \mathrm{mg}^{-1}$ and $0.25 \mathrm{mg} \mathrm{l}^{-1}$, respectively. From an oenological point of view, these compounds produced during fermentation contribute significantly to the desirable aspects of the bouquet of wine, bringing fruity and flowery flavours (Rapp and Mandery, 1986). Non-Saccharomyces wine yeasts are good producers of esters and their use has been suggested as mixed starters together with $S$. cerevisiae to improve the sensory properties of wine. It was reported that yeast strains of $H$. guilliermondii are able to promote the esterification of various alcohols such as ethanol, geraniol, isoamyl alcohols and 2-phenylethanol (Rojas et al., 2001).
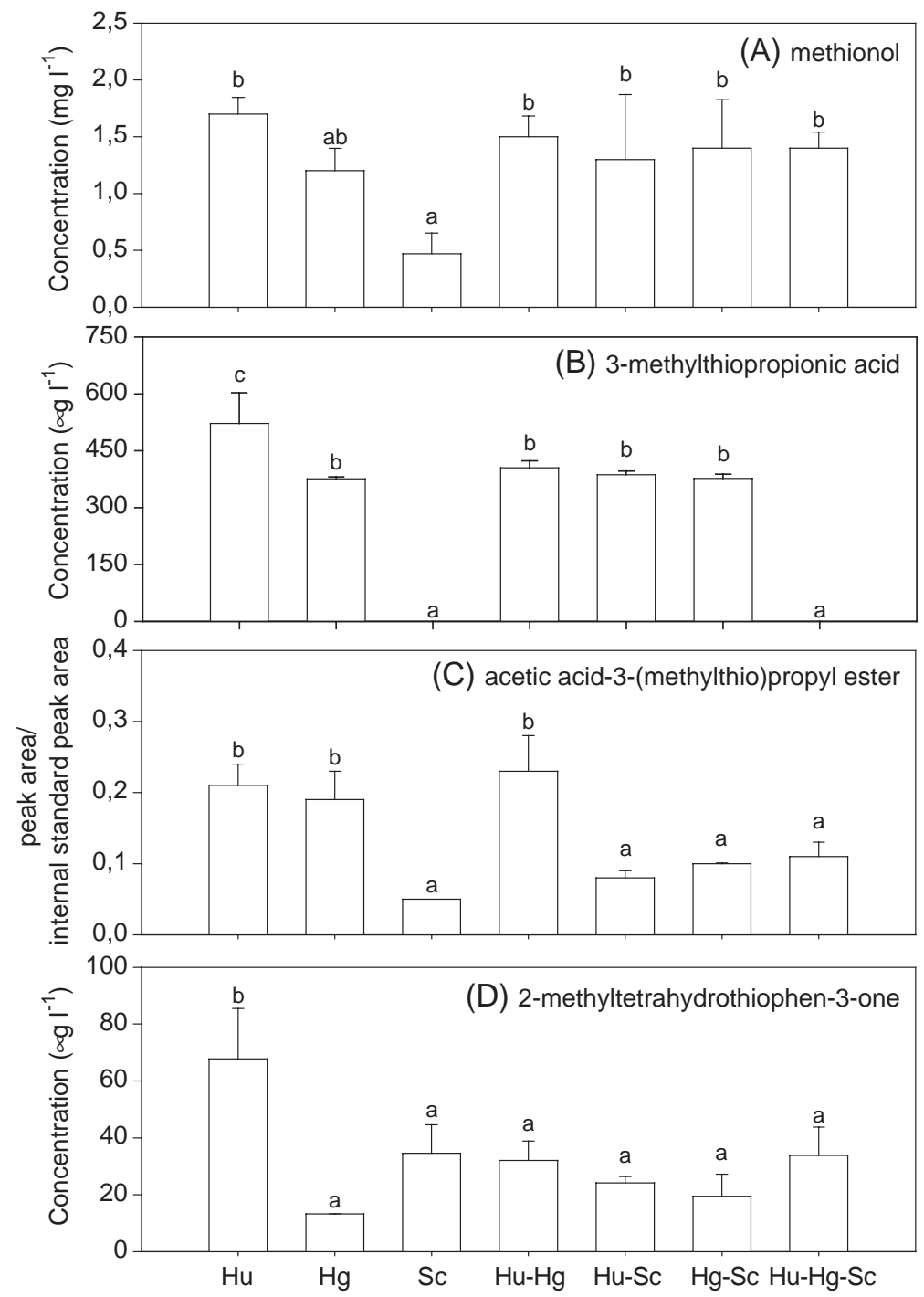

Fig. 4. Concentration of heavy sulphur compounds in pure and mixed cultures of H. uvarum (Hu), H. guilliermondii (Hg) and S. cerevisiae (Sc) on a commercial medium. (A) Methionol, (B) 3-methylthiopropionic acid, (C) acetic acid-3-(methylthio)propyl ester, (D) 2-methyltetrahydrothiophen-3-one. Values not sharing the same superscript letter on top bar are different according to the Tukey test. Vertical bars represent standard deviation. 


\section{Heavy sulphur compounds}

Under the conditions tested, production of heavy sulphur compounds was influenced by the yeast strain used. In general, pure cultures of $H$. uvarum led to the highest production of heavy sulphur compounds. In pure cultures, the fermented medium by $S$. cerevisiae presented $470 \mu \mathrm{g}^{-1}$ of methionol, whereas higher amounts were found in fermented media by apiculate yeasts (Fig. 4A). Growth of apiculate yeasts increased methionol content in mixed cultures. 3-Methylthiopropionic acid (Fig. 4B) was not detected in a pure culture of $S$. cerevisiae, which also presented a low content in acetic acid-3-(methylthio)propyl ester (Fig. 4C). A lower production of acetic acid-3-(methylthio)propyl ester was also obtained in mixed cultures with $S$. cerevisiae. The highest content in 2-methyltetrahydrothiophen-3-one was obtained for a pure culture of H. uvarum; however, growth of this strain had no effect on 2-methyltetrahydrothiophen-3-one concentration in mixed cultures (Fig. 4D). Methionol is present in wines at concentrations up to $5 \mathrm{mg}^{-1}$, and above its threshold value $\left(1.2 \mathrm{mg} \mathrm{l}^{-1}\right.$ in hydroalcoholic solution) it attributes a cauliflower aroma. 2Methyltetrahydrothiophen-3-one (metallic, natural gas odour) and acetic acid-3-(methylthio)propyl ester (cooked potatoes aroma) are usually found in wines at levels below their threshold value. The concentration of 2-methyltetrahydrothiophen-3-one in wines is usually lower than $60 \mu \mathrm{g} \mathrm{I}^{-1}$; however, in reduced wines, with disagreeable odours, it is present at concentrations higher than $100 \mu \mathrm{g}^{-1}$. 3-Methylthiopropionic acid has a limit of perception of $50 \mu \mathrm{g} \mathrm{1^{-1 }}$ (in hydroalcoholic solution), but it can be found in wines at higher contents, up to $310 \mu \mathrm{g}^{-1}$ (Anocibar Beloqui and Bertrand, 1995; Ribéreau-Gayon et al., 2000; Mestres et al., 2000).

\section{Conclusions}

Results presented here show that apiculate yeasts are able to grow in the presence of $S$. cerevisiae and influence the composition of the fermented media. $H$. guilliermondii showed desirable growth kinetic parameters and the ability to produce high levels of 2-phenylethyl acetate and 2-phenylethanol. Growth of apiculate yeasts together with $S$. cerevisiae reduced the content of 2-methyl-1-propanol, when compared with a pure culture of $S$. cerevisiae. Pure cultures of $H$. guilliermondii and S. cerevisiae showed similar contents of methionol and 2-methyltetrahydrothiophen-3-one, but $H$. guilliermondii produced higher levels of acetic acid-3-(methylthio)propyl ester and 3methylthiopropionic acid. Concentrations of heavy sulphur compounds were also higher in a pure culture of $H$. uvarum than in a pure culture of $S$. cerevisiae. Nevertheless, except for methionol, levels of heavy sulphur compounds in mixed cultures of apiculate yeasts with $S$. cerevisiae were similar to those obtained in a pure culture of $S$. cerevisiae.

Although further research is needed, results obtained in this work on growth of Hanseniaspora strains on simple media, and reports in literature on growth of apiculate yeasts on grape musts, suggest that the use of mixed cultures in wine fermentation processes, combined with vinification technology, may lead to the production of wines with different characteristics.

\section{Acknowledgements}

The authors gratefully acknowledge the financial support from FCT and FSE (III Quadro Comunitário de Apoio) and PAMAF (INIA, Project 2025).

\section{References}

Anocibar Beloqui, A., Bertrand, A., 1995. Study of sulfur compounds in wine: preliminary results. Italian Journal of Food Science 3, 279-288.

Barnett, J.A., Payne, R.W., Yarrow, D., 1990. Yeasts, Characteristics and Identification. Cambridge University Press, Cambridge.

Benda, I., 1982. Wine and brandy. In: Reed, G. (Ed.), Prescott and Dunn's industrial microbiology. Avi Technical Books, Westport, pp. $292-402$.

Charoenchai, C., Fleet, G.H., Henschke, P.A., 1998. Effects of temperature, $\mathrm{pH}$, and sugar concentration on the growth rates and cell biomass of wine yeasts. American Journal of Enology and Viticulture 49, 283-288.

Ciani, M., Maccarelli, F., 1998. Oenological properties of nonSaccharomyces yeasts associated with wine-making. World Journal of Microbiology and Biotechnology 14, 199-203.

Ciani, M., Picciotti, G., 1995. The growth kinetics and fermentation behaviour of some non-Saccharomyces yeasts associated with wine-making. Biotechnology Letters 17, 1247-1250.

Constantí, M., Poblet, M., Arola, L., Mas, A., Guillamón, J., 1997. Analysis of yeast populations during alcoholic fermentation in a 
newly established winery. American Journal of Enology and Viticulture 48, 339-344.

Egli, C.M., Edinger, W.D., Mitrakul, C.M., Henick-Kling, T., 1998. Dynamics of indigenous and inoculated yeast populations and their effect on the sensory character of Riesling and Chardonnay wines. Journal of Applied Microbiology 85, 779-789.

Fleet, G.H., 2003. Yeast interactions and wine flavour. International Journal of Food Microbiology 86, 11-22.

Fleet, G.H., Heard, G.M., 1993. Yeasts-growth during fermentation. In: Fleet, G.H. (Ed.), Wine Microbiology and Biotechnology. Harwood Academic Publishers, Chur, Switzerland, pp. 27-55.

Fleet, G.H., Lafon-Lafourcade, S., Ribéreau-Gayon, P., 1984. Evolution of yeasts and lactic acid bacteria during fermentation and storage of Bordeaux wines. Applied and Environmental Microbiology 48, 1034-1038.

Gao, C., Fleet, G.H., 1988. The effects of temperature and $\mathrm{pH}$ on the ethanol tolerance of the wine yeasts. Saccharomyces cerevisiae, Candida stellata, and Kloeckera apiculata. Journal of Applied Bacteriology 65, 405-409.

Gil, J., Mateo, J., Jiménez, M., Pastor, A., Huerta, T., 1996. Aroma compounds in wine as influenced by apiculate yeasts. Journal of Food Science 61, 1247-1266.

Goto, S., 1980. Changes in the wild yeast flora of sulphited grape musts. Journal of Institute of Enology and Viticulture Yamanashi University $15,29-32$.

Hansen, H., Nissen, P., Sommer, P., Nielsen, J.C., Arneborg, N., 2001. The effect of oxygen on the survival of non-Saccharomyces yeasts during mixed cultures fermentations of grape juice with Saccharomyces cerevisiae. Journal of Applied Microbiology 91, 541-547.

Heard, G.M., Fleet, G.H., 1985. Growth of natural yeast flora during the fermentation of inoculated wines. Applied and Environmental Microbiology 50, 727-728.

Herraiz, T., Reglero, G., Herraiz, M., Martín-Alvarez, P., Cabezudo, M.D., 1990. The influence of the yeast and type of culture on the volatile composition of wines fermented without sulfur dioxide. American Journal of Enology and Viticulture 41, 313-318.

Kunkee, R.E., 1984. Selection and modification of yeasts and lactic acid bacteria for wine fermentation. Food Microbiology $1,315-332$.

Lambrechts, M.G., Pretorius, I.S., 2000. Yeast and its importance to wine aroma. A review. South African Journal of Enology and Viticulture 21, 97-129.

Lema, C., Garcia-Jares, C., Orriols, I., Ângulo, L., 1996. Contribution of Saccharomyces and non-Saccharomyces populations to the production of some components of Albariño wine aroma. American Journal of Enology and Viticulture 47, 206-216.

Lilly, M., Lambrechts, M.G., Pretorius, I.S., 2000. Effect of increased yeast alcohol acetyltransferase activity on flavour profiles of wine and distillates. Applied and Environmental Microbiology 66, 744-753.

Martinez, J., Millan, C., Ortega, J.M., 1989. Growth of natural flora during the fermentation of inoculated musts from 'Pedro Ximenez' grapes. South African Journal of Enology and Viticulture 10, 31-35.

Mateo, J., Jimenez, M., Huerta, T., Pastor, A., 1991. Contribution of different yeasts isolated from musts of Monastrell grapes to the aroma of wine. International Journal of Food Microbiology 14, $153-160$.

Mestres, M., Busto, O., Guasch, J., 2000. Analysis of organic sulfur compounds in wine aroma. Journal of Chromatography, A 881, $569-581$.

Moreira, N., Guedes de Pinho, P., Vasconcelos, I., 2004. Method for analysis of heavy sulphur compounds using gas chromatography with flame photometric detection. Analytica Chimica Acta 513, 183-189.

Rapp, A., Mandery, H., 1986. Wine aroma. Experientia 42, $873-884$

Rapp, A., Versini, G., 1991. Influence of nitrogen compounds in grapes on aroma compounds of wines. In: Rantz (Ed.), Proceedings of the International Symposium on Nitrogen in Grapes and Wine. American Society for Enology and Viticulture, Davis, CA, pp. 156-164.

Rauhut, D., 1993. Production of sulfur compounds. In: Fleet, G.H. (Ed.), Wine Microbiology and Biotechnology. Harwood Academic Publishers, Chur, Switzerland, pp. 183-242.

Ribéreau-Gayon, P., Glories, Y., Manjean, A., Dubourdieu, D., 2000. Handbook of Enology. The chemistry of wine stabilization and treatments, vol. 2. John Wiley and Sons Ltd, Chichester.

Rojas, V., Gil, J., Piñaga, F., Manzanares, P., 2001. Studies on acetate ester production by non-Saccharomyces wine yeasts. International Journal of Food Microbiology 70, 283-289.

Rojas, V., Gil, J., Piñaga, F., Manzanares, P., 2003. Acetate ester formation in wine by mixed cultures in laboratory fermentations. International Journal of Food Microbiology 86, $181-188$

Romano, P., Suzzi, G., Comi, G., Zironi, R., Maifreni, M., 1997a. Glycerol and other fermentation products of apiculate wine yeasts. Journal of Applied Microbiology 82, 615-618.

Romano, P., Suzzi, G., Domizio, P., Fatichenti, F., 1997b. Secondary products formation as a tool for discriminating non-Saccharomyces wine strains. Antonie van Leeuwenhoek 71, 239-242.

Romano, P., Fiore, C., Paraggio, M., Caruso, M., Capece, A., 2003. Function of yeasts species and strains in wine flavour. International Journal of Food Microbiology 86, 169-180.

Schütz, M., Gafner, J., 1993. Analysis of yeast diversity during spontaneous and induced alcoholic fermentations. Journal of Applied Bacteriology 75, 551-558.

Soufleros, E., Bertrand, A., 1979. Rôle de la souche de levure dans la production des substances volatiles en cours de la fermentation du jus du raisin. Connaissance de la Vigne et du Vin 13, $181-198$.

Velázquez, J., Longo, E., Sieiro, C., Cansado, J., Calo, P., Villa, T., 1991. Improvement of the alcoholic fermentation of grape juice with mixed cultures of Saccharomyces cerevisiae wild strains. Negative effect of Kloeckera apiculate. World Journal of Microbiology and Biotechnology 7, 485-489.

Zironi, R., Romano, P., Suzzi, G., Battistutta, F., Comi, G., 1993. Volatile metabolites produced in wine and sequential cultures of Hanseniaspora guilliermondii or Kloeckera apiculata and Saccharomyces cerevisiae. Biotechnology Letters 15, 235-238.

Zohre, D.E., Erten, H., 2002. The influence of Kloeckera apiculata and Candida pulcherrima yeasts on wine fermentation. Process Biochemistry $38,319-324$. 